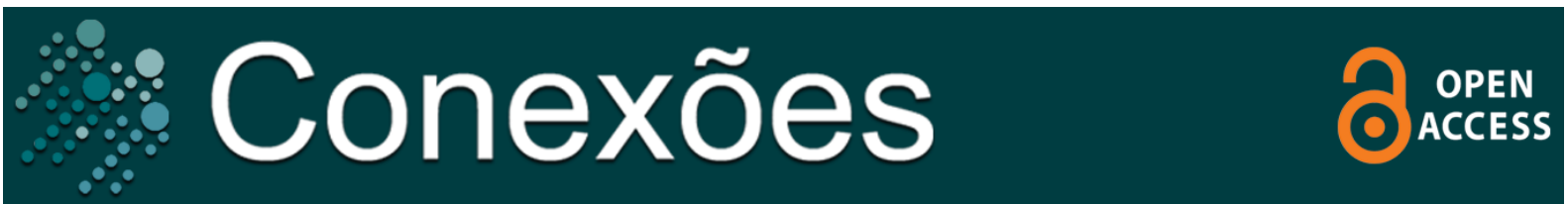

Artigo de Revisão

\title{
Educação Física escolar no ensino médio noturno: um estado da arte
}

\author{
School Physical Education at night high school: \\ a state of the art
}

\section{Educación física escolar en la escuela secundaria nocturna: un estado del arte}

\author{
Antonio Jansen Fernandes da Silva ${ }^{1}$ \\ Allyson Carvalho de Araújo ${ }^{2}$ \\ Antônio de Pádua dos Santos ${ }^{2}$
}

\begin{abstract}
Resumo
Objetivo: Analisar as produções acadêmico-científicas a respeito da Educação Física no Ensino Médio, e em especial, no curso noturno. Metodologia: Realizou-se uma pesquisa bibliográfica do tipo estado da arte nos periódicos nacionais da área, com o qualis CAPES da revista, entre A1 e B2, escritos em português, inglês ou espanhol e que tenham em seu escopo o debate com as ciências humanas e saberes pedagógicos. O mapeamento ocorreu entre janeiro e março de 2019. Resultados e discussão: Percebe-se que dos 2.458 artigos publicados nas 05 revistas, apenas 33 estavam relacionadas com a Educação Física no Ensino Médio, correspondendo assim, a 1,34\% do total das publicações entre 20112018. Identificou-se que o periódico com maior número de publicações no contexto geral da Educação Física pertence à revista Movimento. Isso por si só não legitima o quantitativo de artigos achados sobre a Educação Física no Ensino Médio, ou seja, a revista Pensar a prática possui um número menor de artigos publicados na Educação física no geral, mas um valor numérico, no Ensino Médio, superior comparada a revista Movimento. Conclusão: Nota-se que as principais revistas brasileiras não trazem ou pouco trazem, assuntos relacionados à Educação Física, o Ensino Médio e o Curso Noturno.
\end{abstract}

Palavras-chave: Educação Física. Ensino Médio. Escola.

${ }^{1}$ Secretaria Municipal de Educação de Fortaleza, Fortaleza-CE, Brasil.

2 Universidade Federal do Rio Grande do Norte. Centro de Ciência da Saúde. Departamento de Educação Física, Natal-RN, Brasil.

Correspondência:

Antônio Jansen Fernandes da Silva. Avenida Desembargador Moreira Dionísio Torres, 2875, Fortaleza - CE, CEP 60170-002. Email: jansentimao@hotmail.com 


\begin{abstract}
Objective: To analyze academic-scientific productions about Physical Education in High School, and especially in the evening course. Methodology: A state-of-the-art bibliographic search was carried out in the national journals in the area, with the CAPES of the magazine, between A1 and B2, written in Portuguese, English or Spanish and whose scope is the debate with the humanities and pedagogical knowledge. The mapping took place between January and March 2019. Results and discussion: Of the 2,458 articles published in the 05 magazines, only 33 were related to Physical Education in High School, thus corresponding to $1.34 \%$ of the total publications between 2011-2018. It was identified that the journal with the highest number of publications in the general context of Physical Education belongs to the magazine Movimento. This in itself does not legitimize the number of articles found on Physical Education in High School, that is, the magazine Pensar a prática has a smaller number of articles published in Physical Education in general, but a numerical value in High School, higher compared to the movement Movimento. Conclusion: It is noted that the main Brazilian magazines do not bring or bring little, subjects related to Physical Education, High School and Night Course.
\end{abstract}

Keywords: Physical education. High school. School.

\title{
RESUMEN
}

Objetivo: analizar las producciones académico-científicas relacionadas con la educación física en la escuela secundaria, y especialmente en el curso nocturno. Metodología: Se realizó una búsqueda bibliográfica de vanguardia en las revistas nacionales del área, con los CAPES de la revista, entre A1 y B2, escritos en portugués, inglés o español y cuyo alcance es el debate con las humanidades. y conocimiento pedagógico. El mapeo se realizó entre enero y marzo de 2019. Resultados y discusión: De los 2,458 artículos publicados en las revistas 05, solo 33 estaban relacionados con la Educación Física en la escuela secundaria, lo que corresponde al $1.34 \%$ del total de publicaciones entre 2011-2018. Se identificó que la revista con el mayor número de publicaciones en el contexto general de Educación Física pertenece a la revista Movimento. Esto en sí mismo no legitima el número de artículos encontrados sobre Educación Física en la Escuela Secundaria, es decir, la revista Pensar aática tiene un número menor de artículos publicados en Educación Física en general, pero un valor numérico en la Escuela Secundaria, más alto. comparado con el movimiento Movimento. Conclusión: Se observa que las principales revistas brasileñas no traen o traen poco, temas relacionados con Educación Física, Escuela Secundaria y Curso Nocturno.

Palabras Clave: Educación Física. Escuela secundaria. Colegio. 


\section{INTRODUÇÃO}

A Educação Física vem sofrendo várias mudanças no decorrer de sua história, sendo influenciada pelos aspectos políticos, econômicos, culturais, religiosos, tecnológicos e sociais. A compreensão deste componente curricular no Ensino Médio Noturno, também perpassa por estas questões, numa disputa de poder que, por vezes, tem sua síntese expressa na dimensão legislativa.

A partir da promulgação da Lei de Diretrizes e Bases da Educação Nacional (Lei 9.394/96), a Educação Física passou a ser considerada como componente curricular em grau de igualdade com as demais disciplinas, ou seja, deixou de ser uma mera atividade para se tornar um componente curricular obrigatório, trazendo consigo algumas mudanças significativas comparadas com as leis anteriores, dentre elas podemos destacar: a estruturação didática, a autonomia dada às escolas e sistemas de ensino e um enfoque maior à formação do cidadão. No artigo $26^{\circ}$, parágrafo $3^{\circ}$ dessa lei é citado:

[...] A educação física, integrada à proposta pedagógica da escola, é componente curricular da Educação Básica, ajustando-se às faixas etárias e às condições da população escolar, sendo sua prática facultativa ao aluno;

I - que cumpra jornada de trabalho igual ou superior a seis horas; (Incluído pela Lei no 10.793 , de $1^{\circ} .12 .2003$ )

II - maior de trinta anos de idade; (Incluído pela Lei no 10.793 , de 10.12 .2003 )

III - que estiver prestando serviço militar inicial ou que, em situação similar, estiver obrigado à prática da educação física;

IV - amparado pelo Decreto-Lei $\mathrm{n}^{\circ} 1.044$, de 21 de outubro de 1969 (Incluído pela Lei no 10.793 , de $1^{0} .12 .2003$ )

V - (VETADO); (Incluído pela Lei no 10.793, de 10.12.2003)

VI - que tenha prole (Incluído pela Lei no 10.793, de 10.12.2003)

". (BRASIL, 1996).

Através da leitura crítica do dispositivo legal, percebe-se que não ocorreram mudanças significativas para a área, pois o artigo não detalhava o que se pretendia, consequentemente, acabou deixando lacunas para diferentes interpretações, dentre elas: a justificativa de algumas escolas em dizer que estava cumprindo a lei, quando de fato, ofertavam apenas o componente curricular em algumas séries/anos da Educação Básica e a utilização de outros profissionais ministrando aulas de Educação Física sem a devida formação acadêmica. Apenas em 2001 o termo obrigatório foi acrescentado posteriormente a palavra componente curricular, deixando explícita a cobrança da Educação Física no decorrer da Educação Básica (DARIDO e RANGEL, 2005). Tal inclusão também implicou em um questionamento do porque os demais componentes curriculares com maior tradição no currículo escolar não necessitam da rubrica da obrigatoriedade. Esse debate se prolonga até os dias atuais sob a égide do binômio legalidade X legitimidade (OLIVEIRA, 1999). 
Sabemos dá importância da Educação Física em toda Educação Básica, pois o conhecimento da Cultura Corporal deve trabalhada para formação integral do indivíduo.

Segundo Darido (2009), com a aprovação da LDB em 1996, a Educação Física Noturna passou a ser facultativa para os alunos cursarem e obrigatória a oferta pelas escolas. Caso oferecessem a disciplina, as aulas não seriam contabilizadas na carga horária anual da escola (Parecer do CEE no 178/98). O que revela que a Educação Física noturna continua não ocorrendo, e quando ocorre, é desenvolvida em número reduzido de escolas, e, consequentemente, foram excluídos quase a metade dos alunos do Ensino Médio que provavelmente seriam os maiores beneficiados com os conhecimentos advindos da Cultura Corporal, reforçando a tese da falta de legitimidade ou acolhimento do componente curricular nos espaços escolares.

Em dezembro de 2003 esse quadro foi alterado através da Lei 10.793 que determinou que as aulas de Educação Física passassem a ser facultativas não mais a todas as pessoas que estudassem no período noturno, mas sim àquelas que, independentemente do turno de estudo, se enquadrassem nas seguintes condições: mulheres com prole, trabalhadores, militares e pessoas com mais de trinta anos (BRASIL, 2003).

Enquanto se avançou na concepção da área quando esta se torna um componente curricular, ou seja, uma disciplina que tem um saber, conhecimento a ser apropriado, se retrocede quando é concebida como facultativa, pois reafirma a condição da Educação Física como atividade paralela dentro da estrutura curricular da escola (PICH; PURCOTE FONTOURA, 2013). A Educação Física por fazer parte da Educação Básica precisa estar ciente das possibilidades e dificuldades encontradas durante a formação humana.

Castro (2017) afirma que a Educação Básica enfrenta vários desafios, principalmente no Ensino Médio. Dentre eles: a universalização deste nível de ensino, com qualidade e equidade; a correção do fluxo e baixos índices de aprendizagem; a promoção da educação integral; a adequação do currículo à realidade dos alunos; e as políticas públicas educacionais.

Corrobora com o pensamento de Krawczyk (2011) de que o Ensino Médio brasileiro gera debates polêmicos, seja pelos persistentes problemas de qualidade, acesso e permanência ou pelas controvérsias sobre a sua identidade. A Educação Física, por fazer parte do contexto escolar, não pode e nem deve ficar de fora das discussões efervescentes nas primeiras décadas do século XXI. Com a intenção de balizar a discussão sobre esse componente curricular no Ensino Médio noturno, foi realizado um levantamento bibliográfico para 
aprofundar a temática em questão e para refletir sobre o atual estado da arte acerca do tema. Perante esses questionamentos, partimos com as seguintes perguntas norteadoras: qual a produção acadêmica sobre a Educação Física no Ensino Médio noturno no Brasil? Quais os temas mais tratados no Ensino Médio pela Educação Física Escolar?

Nos últimos anos, pesquisas relacionadas com a Educação Física vêm adotando o uso da metodologia do "estado da arte" como forma de organizar sínteses de produção acadêmico-científica do conhecimento, apresentando o diagnóstico e as implicações para se compreender a construção do saber sobre determinada temática (BRACHT et al., 2011). Neste sentido, tais estudos ganham relevância no momento em que dados provenientes desta pesquisa estão localizados no tempo e no espaço, e podem servir ou direcionar estudos posteriores.

O tipo de estudo genericamente intitulado de "estado da arte" ${ }^{3}$ tem dois principais objetivos: 1 - produzir conhecimento sobre o tema pesquisado; 2fornecer um instrumento para jovens pesquisadores, e também para os experientes no campo da pesquisa, algo que facilite a localização do conhecimento já produzido (BRACHT et al., 2011).

A Educação Física, historicamente, possui um foco direcionado para a subárea da biodinâmica, em detrimento da subárea pedagógica. No estudo realizado por Bracht et al. (2011) apenas 16,5\% dos artigos publicados nos nove principais periódicos nacionais nas últimas três décadas correspondiam a Educação Física Escolar, referente a subárea pedagógica.

Essa situação não é particularidade brasileira. Para Kirki (2010) e Antunes (2010) o mesmo fato ocorre internacionalmente, ou seja, a produção da subárea pedagógica é minoritária, se consideramos o campo com suas diferentes inclinações epistemológicas.

Na pesquisa realizada por Betti, Ferraz e Dantas (2011), apenas $18 \%$ dos manuscritos referenciavam "Educação Física Escolar". Os autores utilizaram como processo investigativo para análise onze revistas nacionais da área, no período de 2004 a 2008. Observou-se que a grande maioria dos achados sobre a Educação Física Escolar concentram-se no Ensino Fundamental.

A Educação Física Escolar busca superar a baixa produção acadêmicocientífica por meio do aumento dos índices de pós-graduação no Brasil

3 Estudos observam a existência de diversas nomenclaturas para o mesmo tipo de estudo, algumas vezes em uma mesma área. Para saber mais consultar Vosgerau e Romanowski (2014). 
relacionados à subárea pedagógica. Nesse contexto, podemos destacar o Programa de Mestrado Profissional para professores da Educação Física (PROEF) e a expansão de periódicos da área. Existem outros fatores que também podem contribuir na valorização da área, como: maior investimento público; qualificação de professores através de formação continuada; incentivos à pesquisa durante a graduação com foco na Educação Física Escolar, entre outros.

Verifica-se nos estudos de Betti, Ferraz e Dantas (2011), o aviso sobre a carência do diálogo acadêmico sobre o Ensino Médio (sendo ou não com o recorte do noturno), em fóruns, congressos, periódicos, dissertações, teses etc. Para Rufino et al. (2016), os dados são alarmantes quando se concentra a análise neste nível de ensino, pois ainda se tem buscado compreender a Educação Física enquanto componente curricular obrigatório.

A escassez de publicações no Ensino Médio é notada no estudo realizado por Rufino et al. (2016), no qual observou-se que somente 1,97\% dos artigos da Educação Física Escolar eram direcionados para esse nível de escolarização. A pesquisa foi desenvolvida entre 2001 a 2010 com a produção acadêmicocientífica das dissertações, teses, livros e artigos da área da Educação Física no Ensino Médio.

Tendo tal cenário como campo de inquietação, percebe-se a importância de se desenvolver a continuidade do mapeamento da produção de conhecimento acadêmico-científico sobre a Educação Física no Ensino Médio a partir de 2010. Considera-se que tal revisão de literatura pode contribuir significativamente para a compreensão do objeto de estudo, somando-se aos estudos outrora realizados (RUFINO et al, 2016) e atualizando o objeto de estudo em questão.

Diante do exposto, o objetivo dessa pesquisa é analisar as produções acadêmico-científicas a respeito da Educação Física no Ensino Médio, em especial no curso noturno, com o intuito de ampliar as discussões sobre esse nível de ensino da Educação Básica Brasileira.

\section{MÉTODO}

Foi utilizado no estudo o método quanti-qualitativo. Os métodos quantitativos supõem uma população de objetos de observação comparável entre si e os métodos qualitativos enfatizam as especificidades de um fenômeno em termos de suas origens e de sua razão de ser (HAGUETTE, 1992). Foi escolhido pelos pesquisadores deste trabalho a análise de apenas artigos publicados em periódicos como fonte da pesquisa. Para Bracht et al. (2011), a produção em periódicos, na maioria das vezes, possui uma maior representatividade comparada a conteúdos publicados em livros, dissertações e teses, visto que periódicos 
divulgam as pesquisas em andamento ou concluídas, boa parte fruto da pressão exercida pelos sistemas de avaliação da CAPES aos programas de pós-graduação.

O estado da arte foi realizado pelos pesquisadores entre janeiro e março de 2019, por meio dos periódicos acessados via internet. Como forma de classificáIos, utilizou-se a WebQualis da CAPES no quadriênio (2013-2016) na área $21^{4}$. Os critérios de inclusão dos periódicos nacionais foram que os artigos fossem classificados de acordo com o estrato Qualis CAPES da revista entre A1 e B2, que fossem escritos em português, inglês ou espanhol e que tenham em seu escopo o debate com as ciências humanas e saberes pedagógicos ${ }^{5}$.

Neste ínterim, a seleção das revistas se deu devido à representatividade nas publicações na área da Educação Física, e seguindo os critérios acima explicitados, estão dispostas no quadro abaixo:

Quadro 1 - Revistas pesquisadas para elaboração do estudo

\begin{tabular}{|c|c|c|}
\hline Revista & Universidade vinculada & Qualis \\
\hline Revista Movimento & $\begin{array}{l}\text { Universidade Federal do Rio Grande do } \\
\text { Sul- UFRGS }\end{array}$ & A2 \\
\hline Revista Motriz & $\begin{array}{l}\text { Universidade Estadual Júlio de Mesquita } \\
\text { Filho- UNESP Rio Claro }\end{array}$ & B1 \\
\hline $\begin{array}{ll}\text { Revista } \quad \text { Brasileira } & \text { de } \\
\text { Educação Física e Esporte }\end{array}$ & Universidade de São Paulo & B1 \\
\hline Pensar a prática & Universidade Federal de Goiás & B2 \\
\hline Motrivivência & Universidade Federal de Santa Catarina & B2 \\
\hline
\end{tabular}

Esses cinco periódicos investigados são alguns dos mais conceituados da área da Educação Física de acordo com a CAPES. O recorte temporal foi realizado do início de 2011 até o final de 2018. Foram analisadas quase todas as edições das respectivas revistas, exceto a Revista Brasileira de Educação Física e Esporte (RBEFE) das edições de 2018, que não se encontravam disponíveis no site da revista no período pesquisado. A escolha por esse período se deu devido à disponibilidade de outros trabalhos de grande relevância para a área da educação física escolar que antecedem a esse estudo. Podemos citar as contribuições de Rufino e Darido (2011) e Dias e Correia (2010).

Foram excluídos da pesquisa: teses, dissertações, capítulos de livros e artigos que não eram publicados em português, inglês ou espanhol. Os critérios de qualidade e de validade metodológica utilizados na pesquisa acompanharam as recomendações de Saur-Amaral (2011) e as investigações dos artigos

\footnotetext{
4 Localiza-se 0 Qualis mer mo do endeço etrônico: https://sucupira.capes.gov.br/sucupira/public/consultas/coleta/veiculoPublicacaoQualis/listaConsult aGeralPeriodicos.jsf

${ }^{5}$ Os pesquisadores se debruçaram apenas nos artigos da subárea sociocultural e pedagógica das referidas revistas, excluindo a biodinâmica
} 
aconteceram por meio do acesso ao site das revistas e da pesquisa de cada edição do período escolhido.

Logo após a amostra dos periódicos, foi realizada a fase da triagem dos artigos, na qual utilizou-se o levantamento de busca por meio dos seguintes descritores: "Educação Física", "Ensino Médio" e/ou "Educação Física noturna". De forma acessória, foi adotado pelos pesquisadores o procedimento de fazer o download das edições das revistas para análise do título do artigo, a leitura do resumo do artigo e a leitura das palavras-chaves. Caso fosse encontrado algo sobre os descritores, eram baixados os artigos completos para o aprofundamento da temática. Esse procedimento foi realizado na seguinte sequência: a) busca de descritores; b) identificação da quantidade de vezes que o termo Educação Física", "Ensino Médio" e/ou "Educação Física noturna", apareciam no texto; c) categorização inicial através da leitura do título e resumo; d) leitura completa do artigo para o aprofundamento e agrupá-las em subcategorias elencadas pelo pesquisador.

Após a busca pelos descritores, foram identificados os artigos intitulados "encontrados". Após a leitura de título e resumo para verificação da pertinência dos mesmos para o estudo, identificou-se os artigos intitulados "selecionados". Somente este segundo grupamento de artigos fizeram parte da análise que se segue.

\section{Resultados e Discussão}

A partir da análise, obteve-se os resultados da produção de conhecimento acadêmico-científica demonstrados no quadro abaixo:

Quadro 2 - A relação entre a quantidade de artigos publicados anualmente em cada periódico e o resultado da busca do termo "Educação Física no Ensino Médio"

\begin{tabular}{|c|c|c|c|c|c|c|c|c|c|c|c|c|c|c|c|c|c|c|}
\hline \multirow[t]{2}{*}{ Revista } & \multicolumn{2}{|c|}{2011} & \multicolumn{2}{|c|}{2012} & \multicolumn{2}{|c|}{2013} & \multicolumn{2}{|c|}{2014} & \multicolumn{2}{|c|}{2015} & \multicolumn{2}{|c|}{2016} & \multicolumn{2}{|c|}{2017} & \multicolumn{2}{|c|}{2018} & \multicolumn{2}{|c|}{ TOTAL } \\
\hline & $E^{1}$ & $S^{2}$ & $E^{1}$ & $S^{2}$ & $\mathbf{E}^{1}$ & $\mathbf{S}^{2}$ & $E^{1}$ & $\mathrm{~S}^{2}$ & $E^{1}$ & $S^{2}$ & $E^{1}$ & $S^{2}$ & $E^{1}$ & $S^{2}$ & $E^{1}$ & $\mathbf{S}^{2}$ & $E^{1}$ & $\mathbf{S}^{2}$ \\
\hline Movimento & 60 & 0 & 60 & 0 & 60 & 0 & 88 & 1 & 80 & 0 & 100 & 1 & 102 & 2 & 96 & 1 & 646 & 5 \\
\hline Motriz & $*$ & $*$ & 76 & 0 & 99 & 0 & 59 & 0 & 55 & 0 & 65 & 0 & 97 & 0 & 61 & 0 & 512 & 0 \\
\hline RBEFE & 60 & 1 & 47 & 0 & 37 & 2 & 40 & 1 & 39 & 0 & 40 & 0 & 59 & 0 & $*$ & 0 & 322 & 4 \\
\hline $\begin{array}{c}\text { Pensar a } \\
\text { prática }\end{array}$ & 45 & 0 & 69 & 0 & 80 & 0 & 80 & 2 & 76 & 4 & 80 & 1 & 80 & 4 & 80 & 3 & 590 & 14 \\
\hline Motrivivência & 36 & 1 & 37 & 0 & 37 & 1 & 41 & 0 & 49 & 0 & 57 & 0 & 66 & 8 & 65 & 0 & 388 & 10 \\
\hline
\end{tabular}

$\mathrm{E}^{1}$ Artigos encontrados $\mathrm{S}^{2}$ Artigos selecionados *Artigos Indisponíveis 
De modo geral, podemos identificar um número bastante variável entre os periódicos, não seguindo uma linearidade dos dados, seja ela, no número de publicações dos artigos ou na periodicidade das edições. A única inferência possível é um discreto aumento de número total de publicações sobre o tema a partir da segunda metade do período investigado.

Observa-se que a Revista Brasileira de Educação Física e Esporte (RBEFE) não apresenta resultados no quadro em 2018, devido as edições não estarem disponíveis durante o período da investigação no site do periódico. Vale ressaltar que várias tentativas foram feitas, mas sem sucesso. Outra análise identificada no quadro acima é a baixa publicação total de artigos da RBEFE.

Nota-se que o periódico com maior número de artigos publicados, no contexto geral da Educação Física, neste período pertence à revista Movimento. Isso por si só não legitima o quantitativo de artigos achados sobre a Educação Física no Ensino Médio. Em contrapartida, a revista Pensar a prática possui um número menor de artigos publicados no âmbito da Educação física no geral, mas um valor numérico, no Ensino Médio, superior quando comparada a revista Movimento. Um estudo realizado por Bracht et al. (2011) sobre a Educação Física Escolar, que tinha como investigação a produção acadêmica durante três décadas, revelou que a mesma revista conferia o maior destaque ao debate sobre o tema. Bracht et al. (2011, p. 20) diz o seguinte: "a revista pensar a prática, até pelo seu título, parece estar voltada e ser entendida pela comunidade como um espaço fortemente vinculado à temática", conferindo assim, a sua importância para o meio acadêmico.

Analisando a revista Motriz, percebe-se que essa sofre algumas alterações durante o percurso histórico. Em 2015, a revista deixa de ser publicada em português e passa a ser em inglês e, também, conta com a diminuição de publicações na subárea pedagógica.

A partir da investigação do que foi produzido de conhecimento acadêmicocientífico entre 2011-2018 sobre a Educação Física no Ensino Médio, podemos notar que a quantidade de artigos publicados em periódicos vem aumentando nos últimos anos na área da Educação Física Escolar, mas não seguindo o mesmo ritmo de acréscimo das pesquisas da Educação Física da área da biodinâmica. Para Bracht et al (2011) o aumento de artigos, dissertações e teses produzidas desde 1980, no meio acadêmico, seja por meio de periódicos científicos e/ou eventos, tem proporcionado uma maior visibilidade da Educação Física no contexto geral.

O aumento no número de vagas dos cursos de pós-graduação em nível de mestrado e doutorado, tem elevado o quantitativo de teses e dissertações 
produzidas no Brasil, proporcionando um acréscimo na produção acadêmica. $O$ nosso país tem uma concentração maior de pós-graduação em Educação Física na área biodinâmica e, consequentemente, um alto índice de pesquisas acadêmicas comparadas com a área pedagógica e/ou cultural (OLIVEIRA; BARBOSA-RINALDI; PIZANI, 2020).

Os dados entre a quantidade de artigos publicados em periódicos e os achados dos descritores "Educação Física no Ensino Médio", encontram-se no quadro abaixo:

Quadro 3 - A relação entre a quantidade de artigos publicados em periódicos e os achados dos descritores "educação física no ensino médio"

\begin{tabular}{|cccc|}
\hline $\begin{array}{c}\text { Revista } \\
\text { Movimento }\end{array}$ & $\begin{array}{c}\text { Artigos publicados } \\
(\mathbf{2 0 1 1 - 2 0 1 8 )}\end{array}$ & $\begin{array}{c}\text { Artigo "Ed. Física no Ensino } \\
\text { Médio"- } \%\end{array}$ \\
\hline Motriz & 646 & 5 & $0,22 \%$ \\
\hline RBEFE & 512 & 0 & $0,00 \%$ \\
\hline $\begin{array}{c}\text { Pensar a } \\
\text { prática }\end{array}$ & 322 & 4 & $0,16 \%$ \\
\hline Motrivivência & 590 & 14 & $0,63 \%$ \\
\hline Total & 388 & 10 & $0,43 \%$ \\
\hline
\end{tabular}

Mediante a análise dos dados, podemos identificar que, dos 2.458 artigos publicados nas 05 revistas do âmbito nacional, apenas 33 estavam relacionadas com a Educação Física no Ensino Médio, correspondendo assim, a 1,34\% do total das publicações entre 2011-2018.

Após a obtenção dessas informações, fizemos o aprofundamento dos artigos por meio da leitura completa daqueles que tinham relação com a temática. Adotou-se como procedimento metodológico de análise dos dados, a criação de categorias e subcategorias, pois entendemos ser possível e mais produtivo o estabelecimento de subcategorias, uma vez que é um trabalho que possibilita maior detalhamento das categorias adotadas. Foi dividido em 07 categorias de ordem numérica decrescente dos achados: conteúdos da Educação Física, intervenção pedagógica, reforma do Ensino Médio, fundamentação teórica, diagnóstico da realidade escolar, políticas públicas educacionais e outros. Encontra-se no quadro abaixo a classificação das categorias e subcategorias dos artigos referentes à Educação Física no Ensino Médio: 
Quadro 4 - Classificação das categorias e subcategorias dos artigos referentes à educação física no ensino médio quanto a sua temática

\begin{tabular}{|c|c|}
\hline $\begin{array}{c}\text { Categorias em ordem } \\
\text { decrescente; números de } \\
\text { artigos }(\%)\end{array}$ & Subcategorias/ Quantidades \\
\hline $\begin{array}{l}\text { 1- Conteúdos da Educação } \\
\text { Física- } n=09(25,8 \%)\end{array}$ & $\begin{array}{l}\text { Dança- } 03 \\
\text { Esporte- } 02 \\
\text { Práticas Corporais-01; Corporeidade- 01; Saúde- } \\
01 \text {; Educação física inclusiva- } 01\end{array}$ \\
\hline $\begin{array}{l}\text { 1- Intervenção pedagógica } \\
n=09(25,8 \%)\end{array}$ & $\begin{array}{l}\text { Prática Pedagógica- } 04 \\
\text { Formaçãa Profissional- } 02 \\
\text { Avaliação em educação física- } 02 \\
\text { Conhecimento do professor sobre gênero- } 01\end{array}$ \\
\hline $\begin{array}{l}\text { 3- Reforma do Ensino Médio } \\
\text { relacionadas a Educação } \\
\text { Física } n=07(22,5 \%)\end{array}$ & $\begin{array}{l}\text { Currículo- } 02 \\
\text { Formação Profissional- } 02 \\
\text { Aspectos legais da Educação Física- } 02 \\
\text { Prática Pedagógica- } 01\end{array}$ \\
\hline $\begin{array}{l}\text { 4- Fundamentação teórica } \\
n=04(12,9 \%)\end{array}$ & $\begin{array}{l}\text { Produção de conhecimento/Estado da arte- } 02 \\
\text { Aspectos Epistemológicos, Sociofilosóficos- } 01 \\
\text { Legislação da educação física- } 01\end{array}$ \\
\hline $\begin{array}{l}\text { 5- Diagnóstico da realidade } \\
\text { escolar } n=02(6,4 \%)\end{array}$ & $\begin{array}{l}\text { Avaliação dos alunos através de teste de } \\
\text { Capacidades Físicas- } 01 \\
\text { Estudo de caso sobre aspectos legais da Educação } \\
\text { Física- } 01\end{array}$ \\
\hline $\begin{array}{l}\text { 6- Políticas Públicas } \\
\text { Educacionais } n=01(3,2 \%)\end{array}$ & Exame Nacional do Ensino Médio (ENEM)- 01 \\
\hline 6- Outras $n=01(3,2 \%)$ & Não identificados a subcategorias- 01 \\
\hline
\end{tabular}

As categorias que obtiveram maiores valores numéricos foram as seguintes: conteúdos da Educação Física e a intervenção pedagógica, cada qual com 09 artigos (25,8\%). Na Educação Física ainda encontramos muitos artigos que versam sobre O QUE ENSINAR? no Ensino Médio. No estudo realizado por Matos et al (2013), a presença de um elevado número de autores (215), instituições (220) e grupos (126), ao longo das três décadas estudadas, tem sinalizado a consolidação do debate sobre conteúdo de ensino da Educação Física.

A subcategoria "dança" aparece em três artigos. Segundo Darido et al. (2017), a dança, enquanto conteúdo da escola, não aparece da forma como deveria, uma vez que sua prática corporal é facilitada por utilizar poucos espaços, sendo essa a realidade da maioria das escolas brasileiras. Percebe-se que nos últimos anos houve um aumento do número de artigos que desenvolvem a dança, apontando novas possibilidades de tratá-la nas instituições escolares.

A categoria "Intervenção Pedagógica" engloba os artigos que reúnem características da ação pedagógica dos professores. Nota-se na subcategoria a maior aparição da "prática pedagógica", presente em quatro artigos. Isso corrobora com Caparroz e Bracht (2007), que questionam justamente qual seria o espaço e o lugar da prática pedagógica dos professores de Educação Física: discutir 
apenas a epistemologia ou a didática para sua ação docente? Os autores ressaltam a necessidade de não ser um mero reprodutor de técnicas de ensinoaprendizagem, e, sim, um professor-pesquisador da sua própria práxis. Sabemos que um professor progressista deve agir através da ação-reflexão-ação na sua prática pedagógica. A aproximação da universidade com a escola pode contribuir para a melhoria da ação docente, tanto do Ensino Superior como da Educação Básica. Para Dias e Correia (2013), na maioria das vezes, quem está no cotidiano escolar não acompanha o que vem sendo produzido pelos pesquisadores. Por outro lado, os mesmos não possuem dados suficientes de como está ocorrendo a prática docente em sala de aula.

A terceira categoria com o maior número de resultados foi a da reforma do Ensino Médio relacionada à Educação Física, com 07 artigos (22,5\%). A revista Motrivivência publicou uma edição especial em 2017 sobre a Educação Física no Ensino Médio, devido à aprovação, pelo congresso, da Medida Provisória No 13.415/17, que alterava diversos itens da Lei de Diretrizes e Bases da Educação Nacional-LDB No 9394/96 e instituindo o "novo" Ensino Médio. Implicando-a significativamente em três campos da Educação Física escolar, a saber: na formação de professores, no trabalho docente e no ensino da Educação Básica. A iniciativa de publicar uma edição para ampliar o debate e discussões acerca da temática, trouxe contributos para a área, não da forma como se pensava, mas diminuímos os prejuízos com tal medida provisória.

A Educação Física com essa medida provisória deixou inicialmente de ser um componente curricular obrigatório como as demais (exceto matemática e português). Lembramos que diversas universidades, movimentos sociais, entidades sindicais, associações e dentre outras, abriram os debates políticopedagógicos sobre a imposição adotada pelo governo vigente. Percebeu-se, também, que a manifestação obrigou o governo a criar, no Ensino Médio, o itinerário formativo integrado, que se traduz na composição de componentes curriculares da Base Nacional Comum Curricular (BRASIL, 1996).

A revista Motrivivência recebeu 16 artigos de pesquisadores da área sobre a temática, selecionando 07 para serem publicados na edição especial, intitulada "Educação Física no Ensino Médio".

As subcategorias referentes à reforma do Ensino Médio vêm abordando assuntos que configuram expressivamente na lógica deste nível de escolarização. A edição especial da revista Motrivivência preza pelo equilíbrio numérico nas publicações dos artigos, ou seja, dois textos para cada tema (currículo, prática pedagógica e formação profissional) e um artigo que discorre sobre os aspectos legais da Educação Física. Os trabalhos publicados debruçam nas principais dimensões para a melhoria da qualidade do ensino, dentre elas: organização curricular; formação humana (trabalho, ciência, cultura e tecnologia); formação 
inicial e continuada; e concepções de conhecimento. Isso demonstra a preocupação da área com as questões que afetam não só a área, mas a sociedade.

A maneira como foi efetivada a medida provisória (MP) No 746/2016, que ficou conhecida como a "MP da reforma do Ensino Médio" no Brasil, coloca em segundo plano questões basilares à garantia de uma educação de qualidade social: as condições objetivas e as infraestruturas das escolas, a profissionalização e a valorização dos profissionais da educação, a relação discente-turma-docente, a consideração dos jovens como sujeitos socioculturais, a inovação nas/das práticas pedagógicas (GARIGLIO; ALMEIDA JúNIOR; OLIVEIRA, 2017).

A categoria "fundamentação teórica" ficou com a quarta colocação em textos publicados nas revistas, ou seja, 04 (12,9\%) artigos com as seguintes subcategorias: estado da arte (02); aspectos epistemológicos, socio-filosóficos (01); e legislação da Educação Física (01). Vale destacar a maior aparição dos trabalhos relacionados ao estado da arte sobre a Educação Física no Ensino Médio. Os trabalhos de Rufino e Darido (2011) e Dias e Correia (2013) retratam a produção acadêmica sobre esse nível de ensino até 2011.

\section{CONSIDERAÇõES FINAIS}

O presente estudo teve como objetivo analisar não só as produções acadêmico-científicas a respeito da Educação Física no Ensino Médio, como também, os cursos noturnos. Mediante os resultados desta pesquisa, podemos identificar quantitativamente que $(1,34 \%)$ dos artigos pesquisados tratavam sobre a Educação Física no Ensino Médio, e, caso a especificidade fosse direcionada para o turno noturno, não haveria publicação. Podemos notar que as principais revistas brasileiras não trazem, ou pouco trazem, assuntos relacionados à Educação Física, o Ensino Médio e o Curso Noturno.

Portanto, a análise da produção científica sobre o Ensino Médio demonstra um quanti-qualitativo muito abaixo $(1,34 \%)$ do que poderia ser debruçado sobre este nível de ensino, quando comparado ao Ensino Fundamental. Alguns fatores podem ser identificados, como a desvalorização da área pedagógica nos principais periódicos brasileiros, a baixa representatividade da Educação Física nesse nível de escolarização e a baixa implementação de políticas públicas para o fortalecimento da juventude. Evidenciando assim, a necessidade do aumento de estudos e investigações que busquem a melhoria do componente curricular.

Portanto, se faz necessário que novos estudos acerca da temática sejam discutidos, com intuito de qualificar ainda mais a produção acadêmico-cientifica da Educação Física Escolar. 


\section{FinANCIAMENTO}

O presente trabalho foi realizado com apoio da Coordenação de Aperfeiçoamento de Pessoal de Nível Superior - Brasil (CAPES).

\section{NOTAS}

\section{CONFLITOS DE INTERESSE}

Os autores não têm conflitos de interesse, incluindo interesses financeiros específicos e relacionamentos e afiliações relevantes ao tema ou materiais discutidos no manuscrito.

\section{Autoria e COAUtORia}

A autoria é responsável pelos conteúdos do texto. Os autores declaram que participaram de forma significativa na construção e formação desde estudo, tendo, enquanto autor, responsabilidade pública pelo conteúdo deste, pois, contribuíram diretamente para o conteúdo intelectual deste trabalho e satisfazem as exigências de autoria.

Antonio Jansen Fernandes da Silva - Concepção e desenvolvimento (desde a ideia para a investigação ou artigo, criou a hipótese); Desenho metodológico (planejamento dos métodos para gerar os resultados); Supervisão (responsável pela organização e execução do projeto e da escrita do manuscrito); Coleta e tratamento dos dados (responsável pelos experimentos, pacientes, organização dos dados); Análise / interpretação (responsável pela análise estatística, avaliação e apresentação dos resultados); Levantamento da literatura (participou da pesquisa bibliográfica e levantamento de artigos); Redação (responsável por escrever uma parte substantiva do manuscrito).

Allyson Carvalho de Araújo - Desenho metodológico (planejamento dos métodos para gerar os resultados); Supervisão (responsável pela organização e execução do projeto e da escrita do manuscrito); Análise / interpretação (responsável pela análise estatística, avaliação e apresentação dos resultados); Levantamento da literatura (participou da pesquisa bibliográfica e levantamento de artigos); Redação (responsável por escrever uma parte substantiva do manuscrito); Revisão crítica (responsável pela revisão do conteúdo intelectual do manuscrito antes da apresentação final).

Antônio de Pádua dos Santos - Desenho metodológico (planejamento dos métodos para gerar os resultados); Supervisão (responsável pela organização e execução do projeto e da escrita do manuscrito); Análise / interpretação (responsável pela análise estatística, avaliação e apresentação dos resultados); Levantamento da literatura (participou da pesquisa bibliográfica e levantamento de artigos); Redação (responsável por escrever uma parte substantiva do manuscrito); Revisão crítica (responsável pela revisão do conteúdo intelectual do manuscrito antes da apresentação final). 


\section{REFERÊNCIAS}

ANTUNES, Fabiana Helena Chiorboli et al. Um retrato da pesquisa brasileira em educação física escolar: 1999-2003. Motriz, Rio Claro, v. 11, n. 3, p. 179-184, set./dez. 2005. Disponível em: http://www.periodicos.rc.biblioteca.unesp.br/index.php/motriz/article/view/79. Acesso em: 27 jun. 19.

BRASIL. Ministério da Educação. Diretrizes Curriculares nacionais da Educação Básica. Secretaria de Educação Básica. Conselho Nacional da Educação. Câmara Nacional de Educação Básica. Brasília: MEC, SEB, DICEI, 2013. Disponível em:

http://portal.mec.gov.br/index.php?option=com docman\&view=download\&alias $=13448-$ diretrizes-curiculares-nacionais-2013-pdf\&category slug=junho-2013pdf\&Itemid=30192. Acesso em: 15 maio 2019.

BRASIL. Lei no 9.394, de 20 de dezembro de 1996. Leis de Diretrizes e Bases da Educação Nacional. Diário Oficial da União, Brasília, 21 de dezembro de 1996. Disponível em: http://www.planalto.gov.br/ccivil 03/LEIS/L9394.htm. Acesso em: 09 jun. 2019.

BRASIL. Lei no 10.328, de 01 de dezembro de 2003. Publicado no Diário Oficial da União em 02 de dezembro de 2003. Disponível em:

https://www.planalto.gov.br/ccivil 03/Leis/LEIS 2001/L10328.htm. Acesso em: 10 jun. 2019.

BRASIL. Lei n 13.415, de 16 de fevereiro de 2017. Publicado no Diário Oficial da União em 17 de fevereiro de 2019. Disponível em:

http://www.planalto.gov.br/ccivil 03/ Ato2015-2018/2017/Lei/L13415.htm. Acesso em: 16 jun. 2019.

BRASIL. Medida Provisória n0746, de 22 de setembro de 2016. Publicado no Diário Oficial da União em 23 de setembro de 2016. Disponível em:

https://www2.camara.leg.br/legin/fed/medpro/2016/medidaprovisoria-746-22-

setembro-2016-783654-publicacaooriginal-151123-pe.html. Acesso em: 20 jun. 2019.

BETTI, Mauro; FERRAZ, Osvaldo Luiz; DANTAS, Luiz Eduardo Pinto Basto Tourinho.

Educação física escolar: estado da arte e direções futuras. Revista Brasileira de Educação Física e Esporte, São Paulo, v. 25, p. 105-115, dez. 2011. Disponível em:

https://www.scielo.br/scielo.php?pid=S1807-55092011000500011\&script=sci arttext. Acesso em: 23 jul. 2019.

BRACHT, Valter et al. Educação Física Escolar como tema da produção de conhecimento nos periódicos da área no Brasil (1980-2010): parte I. Movimento, Porto Alegre, v. 17, n. 02, p. 11-34, abr./jun. 2011. https://www.redalyc.org/pdf/1153/115319252002.pdf.

Acesso em: 04 maio 2019.

BRACHT, Valter et al. A Educação Física Escolar como tema da produção do conhecimento nos periódicos da área no Brasil (1980-2010): parte II. Movimento, v. 18, n. 2, 2012. Disponível em: https://www.redalyc.org/pdf/1153/115323638001.pdf. Acesso em: 04 maio 2019.

CASTRO, Vanessa Gomes. As atribuições da Educação Física escolar: um enfoque especial no Ensino Médio. Motrivivência, Florianópolis, v. 29, n. 52, p. 124-135, 2017. Disponível em: https://periodicos.ufsc.br/index.php/motrivivencia/article/view/50355. Acesso em: 16 maio 2019. 
CAPARROZ, Francisco Eduardo; BRACHT, Valter. O tempo e o lugar de uma didática da educação física. Revista Brasileira Ciência do Esporte, n. 28, p. 21-37, 2007. Disponível em: https://www.redalyc.org/pdf/4013/401338529003.pdf. Acesso em: 08 jun. 2019.

DARIDO, Suraya Cristina. Educação física na escola e as novas orientações para o ensino médio. In: CONGRESSO NORTE PARANAENSE DE EDUCAÇÃO FÍSICA ESCOLAR, 4., 2009, Londrina. Anais... Londrina: Universidade Estadual de Londrina, p. 157-176, 2009.

Disponível em:

http://www.uel.br/eventos/conpef/conpef4/trabalhos/palestrasurayadarido.pdf. Acesso em: 04 jul. 2019.

DARIDO, Suraya Cristina. Educação física no ensino médio: diagnóstico, princípios e práticas. Ijuí: Ed. Unijuí, 2017.

DARIDO, Suraya Cristina; RANGEL, Irene Conceição Andrade. Educação física na escola: implicações para a prática pedagógica. Rio de Janeiro: Guanabara Koogan, 2005.

DIAS, Diogo Inácio; CORREIA, Walter Roberto. A Educação Física no ensino médio como objeto de estudo da produção acadêmico-científica nos periódicos nacionais. Revista Brasileira Educação Física e Esporte, v. 27, n. 2, p. 277-287, abr./jun. 2013. Disponível em: https://www.scielo.br/scielo.php?pid=S1807-

55092013000200011\&script=sci arttext. Acesso em 07 jun. 2019.

GARIGLIO, José Ângelo; ALMEIDA JUNIOR, Ademir Soares; OLIVEIRA, Claudio Márcio. O "novo" ensino médio: implicações ao processo de legitimação da Educação Física. Motrivivência, Florianópolis, v. 29, n. 52, p. 53-70, set. 2017. Disponível em: https://periodicos.ufsc.br/index.php/motrivivencia/article/view/50339. Acesso em: 19 maio 2019.

HAGUETTE, Teresa Maria Frota. Metodologias Qualitativas na Sociologia. Petrópolis: RJ, Vozes, 1992.

KRAWCZYK, Nora. Reflexão sobre alguns desafios do ensino médio no Brasil hoje. Cadernos de Pesquisa, São Paulo, v. 41, n. 144, p. 752-769, set/dez. 2011. Disponível em: https://www.scielo.br/scielo.php?pid=S0100-

$15742011000300006 \&$ script=sci arttext\&tlng=pt. Acesso em: 16 maio 2020.

KIRK, David. O porquê da pesquisa: estado atual e tendências futuras nas pesquisas em educação física. Movimento, Porto Alegre, v. 16, n. 2, p. 11-43, jun. 2010. Disponível em: https://www.seer.ufrgs.br/Movimento/article/view/12745. Acesso em: 22 jul. 2019.

MATOS, Juliana Martins Cassani et al. A produção acadêmica sobre conteúdos de ensino na educação física escolar. Movimento, Porto Alegre, v. 19, n. 2, p. 123-148, 2013. Disponível em: https://www.redalyc.org/pdf/1153/115326317010.pdf. Acesso em: 18 ago. 2020.

OLIVEIRA, Marco Aurélio Taborda. Existe espaço para o ensino de educação física na escola básica. Pensar a Prática, Goiânia, v. 2, p. 119-135, 1999. Disponível em: https://core.ac.uk/display/26729264. Acesso em 19 jul. 2019.

OLIVEIRA, Lucas Machado; BARBOSA-RINALDI, Ieda Parra; PIZANI, Juliana. Produção de conhecimento sobre ginástica na escola: uma análise de artigos, teses e dissertações. Movimento, Porto Alegre, v. 26, e-26017, 2020.

PICH, Santiago; PURCOTE FONTOURA, Mariana. A cultura escolar da educação física no EJA: o paradoxo entre a ruptura com a noção de atividade e a falta da prática corporal. Educación Física y Ciencia, v. 15, n. 1, 2013. Disponível em: 
http://www.memoria.fahce.unlp.edu.ar/library?a=d\&c=arti\&d=Jpr5843. Acesso em: 09 jul. 2019.

RIO DE JANEIRO. Parecer do Conselho Estadual de Educação número 178/98. Publicado no Conselho Estadual de Educação do Estado do Rio de Janeiro em 1998. Disponível em: http://www.cee.rj.gov.br/pareceres/P_1998-078 normativo.pdf. Acesso em: 13 jun. 2019.

RUFINO, Luiz Gustavo Bonatto; FERREIRA, Aline Fernanda; CARVALHO, Amarílis Oliveira; RICCI, Christiano Streb; DARIDO, Suraya Cristina. Educação Física escolar no ensino médio: analisando o estado da arte. Revista Brasileira de Ciências do Esporte, v. 36, p. S353-S369, abr./jun. 2016. Disponível em:

http://www.rbce.cbce.org.br/index.php/RBCE/article/view/2138. Acesso em: 09 jun. 2019.

RUFINO, Luiz Gustavo Bonatto; DARIDO, Suraya Cristina. A produção científica em pedagogia do esporte: análise de alguns periódicos nacionais. Conexões, Campinas, v. 9, n. 2, p. 130-152, 2011. Disponível em:

https://periodicos.sbu.unicamp.br/ojs/index.php/conexoes/article/view/8637704. Acesso em: 05 maio 19.

SAUR-AMARAL, Irina. A Revisão sistemática da literatura com apoio de Endnote X4 e NVIVO 9. Aveiro, Portugal: GOVCOPP, 2011.

VOSGERAU, Dilmeire Sant'anna Ramos; ROMANOWSKI, Joana Paulin. Estudos de revisão: implicações conceituais e metodológicas. Revista Diálogo Educacional, v. 14, n. 41, p. 165-189, jul. 2014. Disponível em:

http://dx.doi.org/10.7213/dialogo.educ.14.041.DS08. Acesso em: 16 maio 2020.

Recebido em: 10 jun. 2020

Aprovado em: 10 set. 2020

Artigo submetido ao sistema de similaridade Turnitin $®$.

A revista Conexões utiliza a Licença Internacional Creative Commons Atribuição 4.0, preservando assim, a integridade dos artigos em ambiente de acesso aberto.

A Revista Conexões é integrante do Portal de Periódicos Eletrônicos da Unicamp e associado/membro das seguintes instituições:
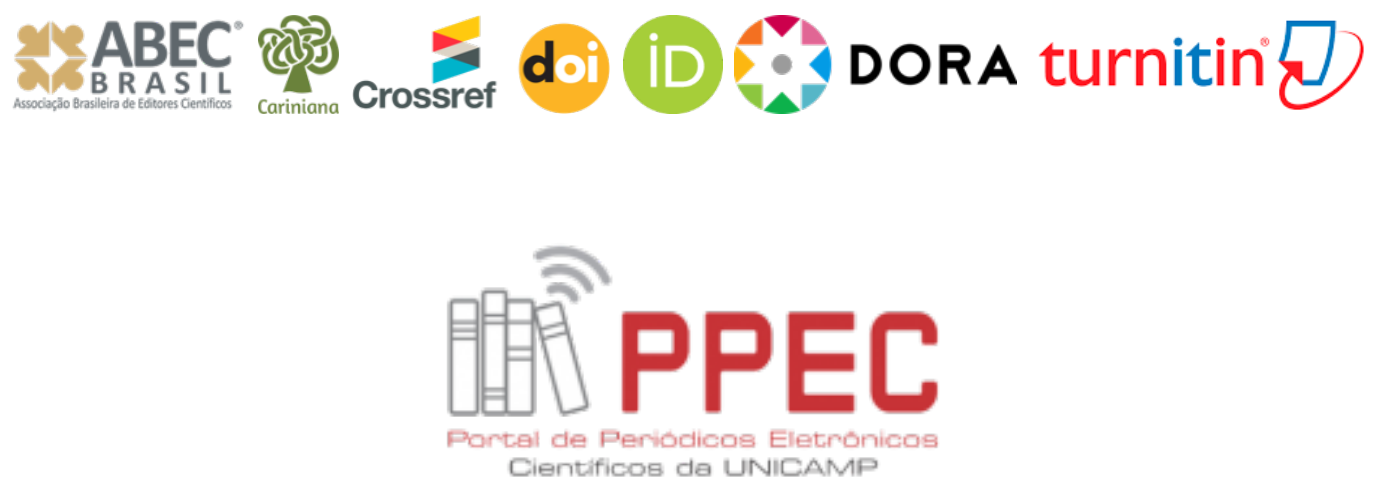